\title{
Family Selection as a Strategy for Stem Borer (Eldana Saccharina Lepidoptera: Pyralidae) Resistance Breeding in South Africa
}

\author{
Marvellous Zhou ${ }^{1,2}$ \\ ${ }^{1}$ South African Sugarcane Research Institute, Durban, RSA \\ ${ }^{2}$ University of Kwazulu-Natal, Pietermaritzburg, RSA \\ Email: Marvellous.Zhou@sugar.org.za
}

How to cite this paper: Zhou, M. (2016) Family Selection as a Strategy for Stem Borer (Eldana Saccharina Lepidoptera: Pyralidae) Resistance Breeding in South Africa. American Journal of Plant Sciences, 7, 2006-2019. http://dx.doi.org/10.4236/ajps.2016.714182

Received: August 15, 2016

Accepted: October 16, 2016

Published: October 19, 2016

Copyright $\odot 2016$ by author and Scientific Research Publishing Inc. This work is licensed under the Creative Commons Attribution International License (CC BY 4.0).

http://creativecommons.org/licenses/by/4.0/

\section{(c) (i) Open Access}

\section{Abstract}

Eldana saccharina is the most damaging stem borer of sugarcane in South Africa causing US\$90 million losses of revenue annually. The breeding strategy at the South African Sugarcane Research Institute is based on evaluating parents for breeding values using progeny data derived from family plots and selecting parents with high breeding values for crossing. Family selection entails selecting whole populations of progenies based on family mean. The objective of this study was to evaluate the contribution of family selection to eldana resistance breeding. Data were collected from stage 1 (seedlings stage) trials. In each plot, stalks were examined for eldana entry and exit holes and stalks with borings were counted. The number of bored stalks was expressed as a percent of total stalks and subjected to analysis of variance. The family broad sense heritabilities ranged from 0.51 - 0.56 compared with 0.17 for Individual Genotype Selection (IGS). Predicted family selection gains ranged from $20 \%$ to $69 \%$ compared with $18 \%$ for IGS indicating the value of family selection. Female parental effects F-values $(1.63-2.01)$ were significant $(P=0.0017-0.0041)$ compared with non-significant male F-values $(1.33-1.41)$ and $(P=0.088-0.1464)$ suggesting maternal effects. Crossing parents with higher resistance such as $96 \mathrm{M} 0058 \times 94 \mathrm{M} 0017$, 87 M0965 $\times 98$ G1166 and 97M0653 $\times 94$ M0017 produced significantly $(P<0.05)$ fewer bored stalks compared with those showing lower resistance $(96 \mathrm{H} 0590 \times$ $95 \mathrm{H} 0167,94 \mathrm{~F} 2694 \times 86 \mathrm{~F} 3326$ and $76 \mathrm{~L} 1295 \times 91 \mathrm{~L} 1492)$ suggesting additive genetic effects and that recurrent selection will be an effective breeding method.

\section{Keywords}

Best Linear Unbiased Predictors, Predicted Selection Gains, Broad Sense Heritability 


\section{Introduction}

Eldana saccharina (E. saccharina) is an indigenous lepidopteran insect pest of sugarcane in Southern Africa and is naturally found in sedges along riverine vegetation [1]. E. saccharina is one of the most damaging stem borers of sugarcane causing significant yield losses estimated at US\$90 million in South Africa [2] [3]. In South Africa, it was first recorded in variety POJ2725 in 1939 and later in NCo376 in 1970 [4] [5]. Currently, the pest is managed in highly infested regions of South Africa using an Integrated Pest Management (IPM) approach combining chemical control, trash burning, reduced harvest age, biological control, sterile insect technology [6]-[8], push pull technology [9] [10] and the cultivation of resistant varieties [11].

In South Africa, E. saccharina was initially identified as a pest of sugarcane in the coastal sugarcane regions in the 1970s [12]. E. saccharina has since spread across the coastal and coastal hinterland areas of the sugarcane growing belt [1]. Incidence of $E$. saccharina damage has been recorded in the Midlands [13] and irrigated regions of South Africa [14] [15]. The high altitude and generally cooler Midlands regions were traditionally known to experience no damage from E. saccharina. The irrigated areas where sugarcane is harvested at 12 months also experienced little or no damage. Previous recommendations for reducing yield losses to E. saccharina included harvesting younger crops [16] [17]. However, there is increasing evidence of E. saccharina damage in the irrigated and Midlands regions. High E. saccharina damage has also been recorded in younger crops, indicating the need to explore higher levels of varietal resistance and methods of accelerating breeding for resistance.

Breeding for E. saccharina resistance started in the 1980s when E. saccharina was recognised as an economic pest of sugarcane [18] [19]. Breeding for E. saccharina resistance involved crossing parents, known to possess high levels of tolerance to produce selection populations. Genotypes in advanced variety trials were later screened in controlled E. saccharina inoculation trials. The screened genotypes were used as parents for E. saccharina resistance breeding, a form of recurrent selection. However, few cultivars (N39, N41) that possess high levels of resistance have been released in recent years, indicating the need to review the current $E$. saccharina resistance breeding strategy. To enhance the recurrent selection breeding strategy for $E$. saccharina resistance, evaluating families in early stages is being explored.

Family selection in sugarcane involves positive selection of whole populations of seedlings from a cross (also known as a family) based on data derived from family plots [20]. Family selection in the seedling stage (Stage I) is widely practiced to different extents for cane yield and sucrose content in Australia [21] [22], USA [23], India [24], Brazil [25] and South Africa [26] [27]. In previous studies, data collected and used for family selection have also been used for evaluating parents. Family selection has produced larger gains compared to individual plant selection for sugarcane yield and sucrose content [27] [28]. However, no application of family selection in pest resistance and particularly E. saccharina resistance breeding has been explored. The reported slow progress as well as the complex and possibly quantitative genetic control of resistance, 
implies that family section would be valuable [29]. Family selection is known to enhance the breeding of quantitatively controlled traits [30]. Further, the data used to evaluate families will also be used to evaluate parents. Parent evaluation using progeny data is more effective particularly complex genomes such as for sugarcane [28].

Limited studies [13] [31] have explored family evaluation for eldana breeding. The objectives of this study are to compare family to individual genotype selection, explore family evaluation in diverse populations, and determine parental effects and the proportion of elite families and parents among populations for eldana breeding.

\section{Materials and Methods}

\subsection{Trials and Locations}

Data were collected from five Stage I trials established across South Africa sugarcane growing regions (Table 1). The coastal long cycle represented the optimum growing conditions in the South African Indian ocean coastline while the coastal short cycle represented eldana escape growing conditions. The Midlands region has short summers and long winters resulting in a 24 month crop cycle. The irrigated region is located in areas with low rainfall, high temperatures and sugarcane crop is produced with irrigation. Trials GML12 (Gingindlovu) and BML12 (Midlands) were planted in 2012 and data collected in 2014 while FML13 (irrigated) and BML13 (Midlands) were established in 2013 and data collected in 2014 and 2015, respectively. UML14 was established at Gingindlovu in 2014 and data were collected in 2015. Trial code GML12 stands for mini-lines (ML) trial for the coastal long cycle breeding programme $(\mathrm{G})$ planted in 2012. BML13 stands for humic soils breeding programme mini-lines trial planted in 2013, FML13 is irrigated breeding programme mini-lines trial planted in 2013 and UML14 stands for coastal short cycle average potential breeding mini-lines trails planted in 2014.

\subsection{Plant Materials and Experimental Design}

The seedlings were germinated from true seed (seed fuzz) in the glasshouse at Mount Edgecombe research station $\left(29.70^{\circ} \mathrm{S}, 31.03^{\circ} \mathrm{E}, 96 \mathrm{~m}\right.$ asl) in Durban, South Africa. A week after germination, the seedlings were hardened outside the glasshouse. When the seedlings were five weeks old, they were transported to Gingindlovu research station for GML12 and UML14 and Pongola research station for FML13. The seedlings for BML12

Table 1. Trials, locations and environments represented.

\begin{tabular}{ccccccc}
\hline Trial & Location & Agro-ecological zone & Coordinates & Altitude & Age & Families \\
\hline GML12 & Gingindlovu & Coastal long cycle & $29.03^{\circ} \mathrm{S}, 31.59^{\circ} \mathrm{E}$ & $93 \mathrm{~m}$ & $15-18$ & 12 \\
BML12 & Bruyns Hill & Midlands Humic soils & $29.42^{\circ} \mathrm{S}, 30.68^{\circ} \mathrm{E}$ & $1012 \mathrm{~m}$ & 24 & 111 \\
BML13 & Bruyns Hill & Midlands Humic soils & $29.42^{\circ} \mathrm{S}, 30.68^{\circ} \mathrm{E}$ & $1012 \mathrm{~m}$ & 24 & 127 \\
FML13 & Pongola & Irrigated & $27.42^{\circ} \mathrm{S}, 31.59^{\circ} \mathrm{E}$ & $301 \mathrm{~m}$ & 12 & 253 \\
UML14 & Gingindlovu & Coastal short cycle & $29.03^{\circ} \mathrm{S}, 31.59^{\circ} \mathrm{E}$ & $93 \mathrm{~m}$ & $12-14$ & 118 \\
\hline
\end{tabular}


and BML13 remained at Mount Edgecombe research station. The seedlings were left to acclimatise for a week at the sites and then transplanted into air bricks laid out on a concrete slab. The air bricks were filled with a mixture of sand, soil and baggase compost in the ratio of 1:1:2. The seedlings were left to grow in air-bricks for 10 months until they produced mini-stalks. The seedlings were irrigated three times a day to prevent moisture stress. Fertiliser (N:P:K = 5:1:5) was applied weekly at a rate of $10 \mathrm{~kg}$ per hectare to achieve optimum growth and replenish nutrients lost to leaching.

The trials were laid out as randomised complete block design with three replications per family. After germination, seedlings from each family were divided into three sets and each set was randomized to one of the three replications. Therefore the families were replicated but individual plants within a family were not replicated. The overall design resulted in two plot levels, the family plot (made up of genetically different seedlings) and each individual sub-plot within a family plot planted to a seedling. The families were randomized at planting into airbricks and the same design was used at field planting. The growing conditions in the airbricks were uniform because of similar and uniformly prepared soil media and uniform irrigation and therefore no confounding effects were expected due to seedling growth conditions.

At 10 months age, the seedlings produced at least $1 \mathrm{~m}$ long stalks. The vegetative stalks of each seedling were harvested by cutting at the base and topping at the natural breaking point. The vegetative material from each seedling was planted in the field to 1 $\mathrm{m}$ long sub-plot, and spacing between sub-plots in the row was $1 \mathrm{~m}$ and spacing between adjacent rows in was $1.1 \mathrm{~m}$, for BML12 and BML13, $1.2 \mathrm{~m}$ for GML12 and UML14 and $1.4 \mathrm{~m}$ for FML13 planted in a tram-line fashion. The spacing between two tramline rows was equivalent to one unplanted row. Tramline refers to a system where two adjacent rows are planted followed by an unplanted row.

\subsection{Data Collection}

Data were collected from the individual sub-plots within a family plot when crop was 12 month old for FML13 and UML14, 18 months old for GML12 and 24 months old for BML12 and BML13, the recommended harvest ages for the trials. From each family plot, data were collected from the first 20 sub-plots. For GML12, the total number of millable stalks was counted for each genotype plot. All the millable stalks in the genotype plot were stripped of leaves. The stripped stalks were inspected for E. saccharina borer entry and exit holes. All the bored stalks were counted and recorded. The number of bored stalks was divided by the total number of stalks for each individual sub-plot to provide an index of damage, the percent bored stalks [32]. For BML12, BML13, FML13 and UML14, a 20 stalk sample was randomly collected from the first 20 sub-plots. The stalks were examined for eldana entry and exit holes, and the bored stalks were recorded. The percent bored stalks data were subjected to analysis of variance.

\subsection{Data Analysis}

The data for percent bored stalks from BML12, BML13, GML12, FML13 and UML14 
were analysed using Proc Mixed of the Statistical Analysis System [33]. The statistical linear mixed model used was:

$$
Y_{i j k}=R_{i}+F_{j}+F R_{i j}+G(F R)_{k(i j)}
$$

where $Y_{i j k}$ is the percent bored stalks of the $k^{\text {th }}$ genotype plot nested within the $f^{\text {th }}$ family in the $i^{\text {th }}$ replication; $R_{i}$ is the random effect of the $i^{t h}$ replication; $F_{j}$ is the random effect of the $j^{\text {th }}$ family; $F R_{i j}$ is the random interaction effect of the $i^{\text {th }}$ replication by the $j^{\text {th }}$ family and also the error term for the family effect; $G(F R)_{k(i j)}$ is the random effect of the $k^{\text {th }}$ genotype plot nested within the random interaction effect of the $i^{\text {th }}$ replication by the $f^{\text {th }}$ family and was also the residual error.

All variables were treated as random because the populations were a sample of the populations to be planted in the breeding programmes. The data analysis generated variance components. Variance components were generated using the COVTEST option of SAS in the model statement [34]. To determine the parameters for individual plant selection in GML12, the following linear model was used:

$$
Y_{i j k}=G(F)_{k(j)}+G(F R)_{k(i j)}
$$

where $G(F)_{k(j)}$ is the random effect of the genotype nested within a family. The estimate of broad sense heritability $(H)$ for families was calculated as:

$$
H_{F}=\sigma_{F}^{2} /\left(\sigma_{F}^{2}+\frac{\sigma_{F R}^{2}}{r}+\frac{\sigma_{G(F R)}^{2}}{r g}\right),
$$

while the broad sense heritability for a genotype was calculated as:

$$
H_{G}=\sigma_{G(F)}^{2} /\left(\sigma_{G(F)}^{2}+\sigma_{G(F R)}^{2}\right),
$$

where $\sigma_{F}^{2}$ was the variance component of family effects; $\sigma_{F R}^{2}$ was the variance component of the interaction effect of replication by family; $\sigma_{G(F)}^{2}$ was the variance component of the genotype nested within family; $\sigma_{G(F R)}^{2}$ was the residual variance component, $r$ the number of replications and $g$ the number of seedlings sampled per family plot. The standard errors $(S E)$ for $H$ were estimated using formula [35]:

$$
S E=\sqrt{\frac{2(1-H)^{2}[1+H(q-1)]^{2}}{q(q-1)(n-1)}}
$$

where $q$ is the number of observations per family and $n$ is the number of families in the trials. Selection gains $\left(G_{s}\right)$ were estimated using the formula [36]:

$$
G_{s}=k \sigma H
$$

where $k$ is family selection intensity which was $30 \%$ [30]; $\sigma$ is the phenotypic standard deviation. For individual genotypes, the selection intensity was $10 \%$, the expected selection intensity in Stage I. The $G_{s}$ was estimated in units of the trait and expressed as a percent of the overall family mean to allow for easy comparisons across traits and populations.

BLUP analysis for the family data was done using the linear model: 


$$
Y_{i j k}=\mu+F_{j}+R_{i}+G(F R)_{k(i j)}
$$

where $\mu$ is the grand mean. The degrees of freedom for the BLUP were estimated using Satterthwaite's procedure [37] for an appropriate $t$-test. BLUP analysis for the parental effects for GML12 used linear mixed model:

$$
Y_{i j k l}=\mu+R_{i}+F_{j}+M_{k}+G(R F M)_{l(i j k)}
$$

where $F_{j}$ is the random effect of the female parent; $M_{k}$ the random effect of the male parent; $G(R F M)_{l(i j k)}$ was the individual $I^{\text {th }}$ genotype nested within the interaction effect of $i^{\text {th }}$ replication by the $f^{\text {th }}$ female parent by the $k^{\text {th }}$ male parent and was the residual error. Equation 8 was also used for BML12, BML13, FML13 and UML14 but with all Female and Male effects considered fixed. The number of families and parents that were significantly less damaged than trial mean were expressed as a percent of total number of families.

\section{Results and Discussion}

Families produced $47 \%$ larger variances than individual genotypes (Table 2) indicating larger genetic variability between families compared to genetic variability of genotypes within families. Individual genotypes produced $25 \%$ larger error variance than families suggesting that individual genotypes were likely more susceptible to environmental variation that families. Family by replication interaction variance component was sig-

Table 2. Variance components, broad sense heritability $(H)$, selection gains $\left(G_{s}\right)$, percent selection gains $\left(\% G_{s}\right)$ for percent bored stalks for families and individual plant selection.

\begin{tabular}{cccccc}
\hline Selection method & Statistic & Variance & S.E. ${ }^{\ddagger}$ & Z-value & $P>\mathrm{Z}$ \\
\hline$\sigma_{F}^{2 \dagger}$ & 65.38 & 51.74 & 1.26 & 0.1032 \\
$\sigma_{F R}^{2}$ & 122.60 & 46.20 & 2.65 & 0.0040 \\
Family selection & $\sigma_{G(F R)}^{2}$ & 531.42 & 30.21 & 17.59 & 0.0001 \\
$H$ & 0.56 & 0.11 & & \\
$G_{s}$ & 15.06 & & & \\
\% $G_{s}$ & 41.2 & & & \\
Individual plant & Mean \pm stdev & $36.52 \pm 23.05$ & & & \\
Selection & $\sigma_{G(F)}^{2}$ & 44.60 & 31.64 & 1.41 & 0.0793 \\
& $\sigma_{G(F R)}^{2}$ & 662.05 & 46.16 & 14.34 & 0.0001 \\
$H$ & 0.17 & 0.04 & & \\
$G_{s}$ & 6.82 & & &
\end{tabular}

$\dagger \sigma_{F}^{2}=$ family effect variance component, $\sigma_{F R}^{2}=$ family by replication interaction effect variance component, $\sigma_{G(F R)}^{2}=$ genotype nested within family by replication interaction effect variance component, $\sigma_{G(F)}^{2}=$ genotype nested within family variance component, $\ddagger$ S.E. $=$ standard error, stdev $=$ standard deviation, $\mathrm{Z}=\mathrm{Z}$ distribution, $P>$ $\mathrm{Z}=$ probability of larger $\mathrm{Z}$ value. 
nificant $(P=0.004)$ suggesting value of replicating families in trials. Families had 3.3 times larger broad sense heritability than individual genotypes indicating that among a large proportion of the phenotype variability of families was contributed by genetics compared to individual genotypes. The results suggest that selecting for superior families is expected to be more efficient than individual genotypes. Families produced 2.2 times larger predicted selection gains compared to individual genotypes indicating larger genetic gains for eldana resistance breeding would be achieved via family than individual genotype selection.

There were significant $(P<0.05)$ family variance components in BML12 and UML14 (Table 3 ) trials suggesting larger genetic variability for families in these trials. Error variance was highly significant $(P<0.0001)$ in all trials indicating the large influence of the environment on eldana damage across agro-ecological regions. The broad sense heritability ranged from 0.21 in BML13 to 0.60 in UML14 suggesting the large variability in the ability to measure genetic variability among families. However, all the trials had higher broad sense heritability than individual genotypes (Table 2) indicating superiority of family selection even with limited data from a small sample size per family plot. Trial UML14, based at Gingindlovu research station had the highest broad sense heritability, similar to that of GML12 (Table 2). Gingindlovu research station is known to be highly infested with eldana resulting in consistently high levels of damage compared to other sites. Trials BML12, BML13 and FML13 are located in agro-ecological regions where eldana damage has started to increase and thus the low levels of damage. Further, the results suggest that screening families at Gingindlovu research station, a location with high infestation of eldana, would be a more viable option as a strategy to enhance eldana resistance breeding.

Table 3. Variance components, broad sense heritability (H), predicted selection gains (Gs), trial mean, coefficient of determination $\left(\mathrm{R}^{2}\right)$ and coefficient of variation (CV\%) for percent eldana bored stalks in BML12, BML13, FML13 and UML14 trials.

\begin{tabular}{|c|c|c|c|c|}
\hline Effect & BML12 & BML13 & FML13 & UML14 \\
\hline Family variance & $\begin{array}{c}1.94 \pm 0.89^{*} \\
\dagger \mathrm{Z} \text {-value }=2.19 \\
\quad P=0.0144\end{array}$ & $\begin{array}{c}33.2635 \pm 28.52 \\
\text { Z-value }=1.17 \\
\quad P=0.1217\end{array}$ & $\begin{array}{c}0.36 \pm 0.17^{\star} \\
\text { Z-value }=1.35 \\
\quad P=0.0878\end{array}$ & $\begin{array}{c}119.89 \pm 50.40^{\star} \\
\text { Z-value }=2.38 \\
\quad P=0.0087\end{array}$ \\
\hline Error variance & $\begin{array}{c}11.15 \pm 1.09 \\
\mathrm{Z} \text { value }=10.25 \\
\quad P<0.0001\end{array}$ & $\begin{array}{c}379.90 \pm 38.60 \\
\mathrm{Z} \text { value }=9.84 \\
\quad P<0.0001\end{array}$ & $\begin{array}{c}2.14 \pm 0.28 \\
\mathrm{Z} \text { value }=7.73 \\
\quad P<0.0001\end{array}$ & $\begin{array}{c}240.65 \pm 44.30 \\
\mathrm{Z} \text { value }=5.43 \\
\quad P<0.0001\end{array}$ \\
\hline $\mathrm{H}$ & 0.34 & 0.21 & 0.33 & 0.60 \\
\hline Gs & 1.31 & 4.62 & 0.45 & 10.40 \\
\hline$\% \mathrm{Gs}$ & 15.74 & 8.21 & 29.89 & 35.24 \\
\hline Trial mean & $8.34 \pm 3.30$ & $56.29 \pm 19.15$ & $1.51 \pm 1.16$ & $29.50 \pm 14.96$ \\
\hline $\mathrm{R}^{2}$ & 0.47 & 0.59 & 0.73 & 0.80 \\
\hline $\mathrm{CV} \%$ & 39.6 & 34.0 & 88.9 & 50.7 \\
\hline
\end{tabular}

$\nmid \mathrm{Z}$-value $=$ normal probability distribution value; $P=$ Probability of a higher $Z$-value. 
Trials FML13 and UML14 had higher predicted selection gains than BML12 and BML13 suggesting limited genetic gains from breeding for eldana among humic soils populations. The results indicate presence of higher levels of resistance genes within the FML13 and UML14 populations. BML12 and BML13 populations, originating from the Midlands appear to possess very low levels of genetic variability for eldana. These results could be reflecting the breeding strategy employed over several decades where genotype exchange was high and also successful across the coastal and irrigated breeding programmes [38] resulting in the interchange of genetic material across these breeding programmes. Some of the exchanged genotypes were later released as cultivars in both coastal and irrigated regions. Examples are N19, N36 and N41. These cultivars, for example N41 with high levels of eldana resistance have also been used as parents further increasing genetic diversity for eldana for the irrigated region. Very few genotypes from outside Midlands breeding programmes have been successful in the Midlands suggesting that the breeding populations have remained largely isolated with years of little exposure to eldana screening, thus creating populations with narrow genetic diversity for eldana resistance. Strategies to diversity the parent populations for the Midlands including deliberate development of parents with eldana resistance would enhance breeding for resistance.

There were significant $(P<0.05)$ fixed effects for families in all trials with larger F-values and smaller p-values in FML13 and UML14 (Table 4). The significant fixed effects for families indicate that families with significantly lower eldana damage, that is elite families for eldana resistance, could be identified in these populations and more precisely in FML13 and UML14. There were significant $(P<0.01)$ female effects for trials BML12, FML13 and UML14. All trials had non-significant male effects. The results suggest potential existence of maternal effects, a result reported in previous studies [31]. FML13 had significant female by male effect suggesting potential existence of specific combining ability and other genetic interaction for eldana resistance. Further studies are required to quantify the genetic control of eldana resistance in sugarcane breeding.

Using data from GML12, the BLUP for families were estimated (Table 5). Positive and significant $(P<0.05)$ values indicate higher eldana damage while negative and sig-

Table 4. The F-values and their $P$-values for Family, Female, Male, Female ${ }^{\star}$ Male effects for percent eldana bored stalks in trials BML12, BML13, FML13 and UML14.

\begin{tabular}{ccccc}
\hline Effect & BML12 & BML13 & FML13 & UML14 \\
\hline \multirow{2}{*}{ Family } & F-value $=1.57 ;$ & F-value $=1.33 ;$ & F-value $=1.72 ;$ & F-value $=1.94 ;$ \\
& $P$-value $=0.0029$ & $P$-value $=0.0366$ & $P<0.0003$ & $P=0.0022$ \\
Female & F-value $=2.01 ;$ & F-value $=1.22 ;$ & F-value $=1.63 ;$ & F-value $=1.88 ;$ \\
& $P$-value $=0.0017$ & $P$-value $=0.1864$ & $P$-value $=0.0041$ & $P$-value $=0.0048$ \\
Male & F-value $=1.41 ;$ & F-value $=1.14 ;$ & F-value $=1.33 ;$ & F-value $=1.32 ;$ \\
& $P$-value $=0.088$ & $P$-value $=0.3016$ & $P$-value $=0.1464$ & $P$-value $=0.2000$ \\
Female* Male & F-value $=1.39 ;$ & F-value $=0.82 ;$ & F-value $=1.62 ;$ & F-value $=0.94 ;$ \\
& $P$-value $=0.1532$ & $P$-value $=0.7091$ & $P$-value $=0.0442$ & $P$-value $=0.4875$ \\
\hline
\end{tabular}


Table 5. Estimate of best linear unbiased prediction (BLUP) of percent bored stalks in relation to the grand mean, standard error (SE) of BLUP, Satterthwaite estimated degrees of freedom (DF), $\mathrm{t}$-statistic and probability of a larger t-statistic $(P)$ of 12 sugarcane families.

\begin{tabular}{ccccccc}
\hline Family & Female $\times$ Male & BLUP & S.E. & DF & t statistic & $P$ \\
\hline SS0541 & $96 \mathrm{H} 0590 \times 95 \mathrm{H} 0167$ & 15.45 & 4.17 & 641 & 3.71 & 0.0002 \\
UU0077 & $99 \mathrm{~F} 2694 \times 94 \mathrm{H} 0570$ & 4.92 & 4.41 & 641 & 1.11 & 0.2653 \\
UU0480 & $04 \mathrm{X} 0054 \times 97 \mathrm{M} 0653$ & 1.45 & 4.28 & 641 & 0.34 & 0.7355 \\
UU0628 & $94 \mathrm{~F} 2195 \times 86 \mathrm{~F} 3326$ & 9.58 & 4.46 & 641 & 2.15 & 0.0321 \\
UU0859 & $96 \mathrm{M} 0058 \times 94 \mathrm{M} 0017$ & -8.07 & 4.18 & 641 & -1.93 & 0.0540 \\
VV0061 & $90 \mathrm{M} 0971 \times 04 \mathrm{X} 0036$ & -14.44 & 4.17 & 641 & -3.46 & 0.0006 \\
VV0206 & $76 \mathrm{~L} 1295 \times 91 \mathrm{~L} 1492$ & 9.95 & 4.17 & 641 & 2.39 & 0.0173 \\
VV0289 & $88 \mathrm{~L} 0046 \times 85 \mathrm{M} 0977$ & -4.69 & 4.24 & 641 & -1.10 & 0.2696 \\
VV0494 & $85 \mathrm{M} 0987 \times 98 \mathrm{G} 1166$ & 9.65 & 4.18 & 641 & 2.31 & 0.0214 \\
VV0564 & $87 \mathrm{M} 0965 \times 98 \mathrm{G} 1166$ & -11.39 & 4.30 & 641 & -2.65 & 0.0083 \\
VV0685 & $97 \mathrm{M} 0653 \times 86 \mathrm{~F} 3326$ & -4.77 & 4.20 & 641 & -1.14 & 0.2559 \\
VV0908 & $97 \mathrm{M} 0653 \times 94 \mathrm{M} 0017$ & -7.63 & 4.35 & 641 & -1.75 & 0.0801 \\
\hline
\end{tabular}

nificant values indicate lower eldana damage. Families UU0849, VV0061 and VV0564 had significantly fewer eldana bored stalks while families SS0541, UU0628, VV0206 and VV0494 had significantly higher numbers of eldana bored internodes. The results indicate the ability to identify families with higher proportion of resistant genotypes from where selection for individual genotypes should be focused. Families that had fewer eldana bored stalks were largely generated from parents 90M0971, 96M0058, 94M0017, 87M0965, 98G1166, 97M0653 while those with significantly higher damage were generated from 96H0590, 95H0167, 94F2195, 86F3326, 76L1295, 91L1492. The M and G codes reference genotypes originating from breeding programmes based at research stations with high levels of eldana damage while the $\mathrm{H}, \mathrm{F}$ and $\mathrm{L}$ were from breeding programmes with low levels of eldana [11]. Therefore the results suggest potential existence of natural selection and recurrent selection for eldana resistance. Further, the results confirm the narrow genetic diversity for eldana damage in the Midlands populations $(\mathrm{H})$ compared to the coastal populations ( $\mathrm{M}$ and $\mathrm{G})$. However, the results further indicate that recurrent breeding and selection for eldana resistance will be effective and should be pursued for Midlands and Irrigated breeding programmes. Such recurrent selection can be done at Gingindlovu research station where eldana levels are high and the resultant populations tested at their regions for adaptability before being used as elite parents for eldana breeding.

Crossing resistant parents produced resistant families while crossing susceptible parents produced susceptible families (Table 5) suggesting potential existence of additive genetic control for eldana resistance. Further, parent 98G1166 produced a family with significantly higher levels of damage when crossed to 85M0987 and significantly low levels of damage were produced when crossed to parent 87M0965 suggesting po- 
tential existence of genetic interactions for eldana resistance. Further research using di-allel designed crosses is required to determine genetic control for eldana resistance.

Using GML12 data, female and male BLUP values were estimated (Table 6). Female parents 80M0971 and 87M0965 produced significantly lower levels of damage while female parent $96 \mathrm{H} 0590$ had significantly higher levels of damage suggesting that parents imparting resistance can be identified for use in future eldana resistance breeding. However, none of the male parents were significant suggesting potential existence of maternal effects and that probably selecting resistant female parents was more important and the male parent probably contributes deficient traits to the cross.

Because eldana resistance breeding at SASRI has always focused on screening at late stage trials, little knowledge is available on the level of resistance in breeding populations. The proportion of elite families (significantly $P<0.05$ less damage) and elite parents (significantly $P<0.05$ less damage) were calculated from the populations (Table 7). The elite families ranged from $4 \%$ to $9 \%$ suggesting low levels of resistance. Highest proportion of elite families (9.3\%) was in UML14, based at Gingindlovu research station where natural selection in early stage has existed for more generations

Table 6. Female and male best linear unbiased prediction (BLUP), standard error (S.E.) of BLUP, Satterthwaite estimated degrees of freedom (DF), t-statistic and probability of a larger t-statistic $(P>\mathrm{t})$.

\begin{tabular}{ccccccc}
\hline Parent & Role & BLUP & S.E. & DF & t statistic & $P>\mathrm{t}$ \\
\hline 04X0054 & Female & 0.54 & 5.55 & 640 & 0.10 & 0.9222 \\
$76 \mathrm{~L} 1295$ & Female & 7.57 & 5.49 & 640 & 1.38 & 0.1687 \\
$80 \mathrm{M} 0971$ & Female & -12.67 & 5.49 & 640 & -2.31 & 0.0215 \\
$85 \mathrm{M} 0987$ & Female & 9.22 & 5.15 & 640 & 1.79 & 0.0740 \\
$87 \mathrm{M} 0965$ & Female & -11.67 & 5.22 & 640 & -2.23 & 0.0258 \\
$88 \mathrm{~L} 0046$ & Female & -4.55 & 5.53 & 640 & -0.82 & 0.4112 \\
$94 \mathrm{~F} 2195$ & Female & 7.72 & 5.12 & 640 & 1.51 & 0.1320 \\
$96 \mathrm{H} 0590$ & Female & 12.14 & 5.49 & 640 & 2.21 & 0.0275 \\
$96 \mathrm{M} 0058$ & Female & -4.69 & 5.03 & 640 & -0.93 & 0.3512 \\
$97 \mathrm{M} 0653$ & Female & -7.09 & 4.26 & 640 & -1.66 & 0.0964 \\
$99 \mathrm{~F} 2694$ & Female & 3.47 & 5.62 & 640 & 0.62 & 0.5373 \\
$04 \mathrm{X} 0036$ & Male & -2.73 & 4.20 & 640 & -0.65 & 0.5166 \\
$84 \mathrm{M} 0017$ & Male & 2.51 & 3.80 & 640 & 0.66 & 0.5084 \\
$85 \mathrm{M} 0977$ & Male & -0.98 & 4.20 & 640 & -0.23 & 0.8159 \\
$86 \mathrm{~F} 3326$ & Male & 1.17 & 3.35 & 640 & 0.35 & 0.7262 \\
$91 \mathrm{~L} 1492$ & Male & 1.63 & 4.20 & 640 & 0.39 & 0.6982 \\
$94 \mathrm{H} 0570$ & Male & 0.75 & 4.21 & 640 & 0.18 & 0.8593 \\
$94 \mathrm{M} 0017$ & Male & -4.56 & 3.50 & 640 & -1.30 & 0.1929 \\
$95 \mathrm{H} 0167$ & Male & 2.61 & 4.20 & 640 & 0.62 & 0.5342 \\
$97 \mathrm{M} 0653$ & Male & 0.12 & 4.20 & 640 & 0.03 & 0.9779 \\
$98 \mathrm{G} 1166$ & Male & -0.53 & 3.98 & 640 & -0.13 & 0.8949 \\
\hline
\end{tabular}


Table 7. Proportion of elite families and parents for eldana among populations.

\begin{tabular}{ccccccc}
\hline Trial & Families & Elite & $\%$ & Parents & Elite & $\%$ \\
\hline BML12 & 111 & 7 & 6.31 & 67 & 3 & 4.48 \\
BML13 & 127 & 5 & 3.94 & 66 & 2 & 3.03 \\
FML13 & 253 & 12 & 4.74 & 130 & 9 & 6.92 \\
UML14 & 118 & 11 & 9.32 & 94 & 4 & 4.26 \\
Combined & 609 & 35 & 5.75 & 357 & 18 & 5.04 \\
\hline
\end{tabular}

while the lowest was in BML13 where very little natural selection is expected. The proportion elite parents, that were significantly $(P<0.05)$ less damaged ranged from $3 \%$ to 7\%. FML13 had surprising the highest proportion indicating the genotype transfer could have benefited the irrigated breeding programmes in terms of acquiring eldana resistance genes while the Midlands BML13 had the lowest where no transferred genotypes have been successful.

\section{Conclusion}

Family selection will increase genetic gains for eldana resistance in sugarcane breeding in South Africa. Family selection produced larger broad sense heritability and predicted selection gains than individual selection even when using small sample size. There is existence of maternal effects for eldana resistance. Additive genetic effects are likely involved in controlling resistance to eldana damage. Potential sources of resistance exist within the South African breeding populations originating from Gingindlovu research station in the coastal areas where high levels of eldana infestation are present. The presence of high levels of resistance in populations originating from high infestation areas as well those with parents originating from the high infestation areas indicates that natural selection for eldana exists and recurrent breeding and selection can be used to accelerate breeding for eldana resistance. The low proportion of elite families and parents for eldana resistance across the breeding populations indicates the urgency required to initiate population development for eldana resistance. Adopting family evaluation and selection as a strategy to accelerate breeding for eldana resistance is expected to increase resistance levels across all breeding populations in future. However, research to determine conclusively the genetic control for eldana resistance is required as a prerequisite to guide future eldana resistance breeding strategies.

\section{References}

[1] Atkinson, P.R. (1980) On the Biology, Distribution and Natural Host-Plants of Eldana saccharina Walker (Lepidoptera: Pyralidae). Journal of Entomology Society of South Africa, 43, 171-194.

[2] Atkinson, P.R. and Nuss, K.J. (1989) Association between Host-Plant Nitrogen and Infestation of the Sugarcane Borer, Eldana saccharina Walker (Lepidoptera: Pyralidae). Bulletin of Entomology Research, 79, 489-506. http://dx.doi.org/10.1017/S0007485300018460

[3] Rutherford, R.S. (2015) IPM for Eldana Control: An Integrated Pest Management (IPM) 
Approach for the Control of the Stalk Borer Eldana saccharina Walker (Lepidoptera: Pyralidae). South African Sugarcane Research Institute, South Africa.

[4] Carnegie, A.J.M. (1981) Combating Eldana saccharina Walker: A Progress Report. Proceedings of the South African Sugar Technologists Association, 55, 116-119.

[5] Carnegie, A.J.M. (1982) Current Research Programme against Eldana saccharina Walker (Lepidoptera: Pyralidae). Proceedings of the South African Sugar Technologists Association, 56, 95-98.

[6] Mudavanhu, P., Conlong, D.E. and Addison, P. (2011) Performance of Sterilized Eldana saccharina Walker (Lepidoptera: Pyralidae) in Mating Trials. Proceedings of the South African Sugarcane Technologists Association Congress, 86, 287-291.

[7] Mudavanhu, P., Conlong, D.E. and Addison, P. (2012) Impact of Mass-Rearing and Gamma Radiation on Thermal Tolerance of Eldana saccharina Walker (Lepidoptera: Pyralidae). Proceedings of the South African Sugarcane Technologists Association Congress, 86, 311-320.

[8] Mudavanhu, P., Conlong, D.E. and Addison, P. (2013) Release of Irradiated Moths to Suppress Wild Populations of Eldana saccharina Walker (Lepidoptera: Pyralidae). Proceedings of the South African Sugarcane Technologists Association Congress, 86, 311-320.

[9] Cockburn, J.J., Conlong, D.E., Van Den Burg, J. and Bezuidenhout, C.N. (2013) Understanding Adoption of Push-Pull for Control of Eldana saccharina Walker (Lepidoptera: Pyralidae) Using Exploratory Network Analysis. Proceedings of the South African Sugar Technologists Association, 86, 321-327.

[10] Dentinger, D., Conlong, D.E., Rutherford, R.S. and Harraca, V. (2013) Effect of Known Push-Pull Plants on the Behaviour of Eldana saccharina Moths and Larvae. Proceedings of the South African Sugar Technologists Association, 86, 235-239.

[11] Nuss, K.J., Bond, R.S. and Atkinson, P.R. (1986) Susceptibility of Sugarcane to the Borer Eldana saccharina Walker and Selection for Resistance. Proceedings of the South African Sugar Technologists Association, 60, 153-155.

[12] Carnegie, A.J.M. (1974) A Recrudescence of the Borer Eldana saccharina Walker (Lepidoptera: Pyralidae). Proceedings of the South African Sugar Technologists Association, 48, 107 110.

[13] Zhou, M.M. (2015) Selection for Eldana Borer Resistance in Early Stages of Sugarcane Breeding in South Africa. American Journal of Plant Sciences, 6, 2168-2176. http://dx.doi.org/10.4236/ajps.2015.613219

[14] Mazodze, R. and Conlong, D.E. (2003) Edana saccharina (Lepidoptera: Pyralidae) in Sugarcane (Saccharum hybrids), Sedge (Cyperusdigitatus) and Bulrush (Typhalatifolia) in South-Eastern Zimbabwe. Proceedings of the South African Sugarcane Technologists Association Congress, 77, 266-274.

[15] Mazodze, R., Nyanhete, C. and Chidoma, S. (1999) First Outbreak of Eldana saccharina (Lepidoptera: Pyralidae) in Sugarcane in the South-East Lowveld of Zimbabwe. Proceedings of the South African Sugarcane Technologists Association Congress, 73, 107-111.

[16] Inman-Bamber, N.G. (1991) Some Physiological Factors Affecting the Optimum Age and Season for Harvesting Sugarcane. Proceedings of the South African Sugar Technologists Association, 65, 103-108.

[17] Inman-Bamber, N.G. (1994) Effect of Age and Season on Components of Yield of Sugarcane in South Africa. Proceedings of the South African Sugar Technologists Association, 68, 23-27.

[18] Nuss, K.J. and Atkinson, P.R. (1983) Methods Used to Measure the Susceptibility of Sugar- 
cane Varieties to Attack by Eldana saccharina (Walker). Proceedings of the South African Sugarcane Technologists Association Congress, 57, 92-94.

[19] Nuss, K.J. (1991) Screening Sugarcane Varieties for Resistance to Eldana Borer. Proceedings of the South African Sugarcane Technologists Association Congress, 65, 92-95.

[20] Kimbeng, C.A. and Cox, M.C. (2003) Early Generation Selection of Sugarcane Families and Clones in Australia: A Review. Journal of the American Society of Sugar Cane Technologists, 23, 23-29.

[21] Jackson, P.A., Bull, J.K. and McRae, T.A. (1995) The Role of Family Selection in Sugarcane Breeding Programs and the Effect of Genotype X Environment Interactions. Proceedings of the International Society of Sugar Cane Technologists, 22, 261-269.

[22] Kimbeng, C.A., McRae, T.A. and Stringer, J.K. (2000) Gains from Family and Visual Selection in Sugarcane, Particularly for Heavily Lodged Crops in the Burdekin Region. Proceedings of the Australian Society of Sugar Cane Technologists, 22, 163-169.

[23] Tai, P.Y.P., Shine, J.M., Miller, J.D. and Edme, S.J. (2003) Estimating the Family Performance of Sugarcane Crosses Using Small Progeny Test. Journal of the American Society of Sugar Cane Technologists, 23, 61-70.

[24] Shanthi, R.M., Bhagyalakshmi, K.V., Hemaprabha, G., Alarmelu, S. and Nagarajan, R. (2008) Relative Performance of the Sugarcane Families in Early Selection Stages. Sugar Technology, 100, 114-118. http://dx.doi.org/10.1007/s12355-008-0019-8

[25] Pedrozo, C.A., Barbosa, M.H.P., da Silva, F.L., de Resende, M.D.V. and Peternelli, L.A. (2011) Repeatability of Full-Sib Sugarcane Families across Harvests and the Efficiency of Early Selection. Euphytica, 182, 423-430. http://dx.doi.org/10.1007/s10681-011-0521-z

[26] Zhou, M.M. and Lichakane, M.L. (2012) Family Selection Gains for Quality Traits among South African Sugarcane Breeding Populations. South African Journal of Plant and Soil, 29, 143-149. http://dx.doi.org/10.1080/02571862.2012.743606

[27] Zhou, M.M. (2014) Family Evaluation for Sugarcane Yield Using Data Estimated from Stalk Number, Stalk Height and Stalk Diameter. Journal of Crop Improvement, 28, 406-417. http://dx.doi.org/10.1080/15427528.2014.906528

[28] Stringer, J.K., Cox, M.C., Atkin, F.C., Wei, X. and Hogarth, D.M. (2011) Family Selection Improves the Efficiency and Effectiveness of Selecting Original Seedlings and Parents. Sugar Technology, 13, 36-41. http://dx.doi.org/10.1007/s12355-011-0073-5

[29] Nuss, K.J. (1998) Aspects Considered in the Search for New Farms for the Experiment Station. Proceedings of the South African Sugarcane Technologists Association Congress, 72, 42-45.

[30] Hogarth, D.J., Braithwaite, M.J. and Skinner, J.C. (1990) Selection of Sugarcane Families in the Burdekin District. Proceedings of the Australian Society of Sugar Cane Technologists, $12,99-104$.

[31] Zhou, M.M. and Mokwele, A. (2015) Family versus Individual Genotype Selection for Eldana saccharina Resistance in Early Stages of Sugarcane Breeding. South African Journal of Plant and Soil, 22, 1-8.

[32] Leslie, G.W. (2013) Aspects of Sampling Eldana saccharina Walker (Lepidoptera: Pyralidae) Populations and Damage in Sugarcane. Proceedings of the South African Sugarcane Technologists Association Congress, 86, 311-320.

[33] SAS Institute (2012) SAS/STAT User's Guide, Version 9.1.3. SAS Institute, Cary.

[34] Littell, R.C., Milliken, G.A., Stroup, W.W. and Wolfinger, R.D. (2005) SAS System for Mixed Models. 7th Edition, SAS Institute Inc., Cary. 
[35] Becker, W.A. (1992) Manual of Quantitative Genetics. 5th Edition, Academic Enterprises, Pullman.

[36] Allard, R.W. (1960) Principles of Plant Breeding. John Wiley and Sons, New York.

[37] Freund, R.J. and Wilson, W.J. (2003) Statistical Methods. Academic Press, New York.

[38] Parfitt, R.C. and Thomas, D.W. (2001) Final Stage Transfers in a Regional Breeding and Selection Programme for Sugarcane. Proceedings of the South African Sugar Technologists Association, 75, 151-153.

\section{Submit or recommend next manuscript to SCIRP and we will provide best service} for you:

Accepting pre-submission inquiries through Email, Facebook, LinkedIn, Twitter, etc. A wide selection of journals (inclusive of 9 subjects, more than 200 journals)

Providing 24-hour high-quality service

User-friendly online submission system

Fair and swift peer-review system

Efficient typesetting and proofreading procedure

Display of the result of downloads and visits, as well as the number of cited articles

Maximum dissemination of your research work

Submit your manuscript at: http://papersubmission.scirp.org/

Or contact ajps@scirp.org 